\title{
Review
}

Journal of Innate

Immunity
J Innate Immun 2013;5:324-335

DOI: $10.1159 / 000348828$
Received: November 1, 2012

Accepted after revision: February 12, 2013

Published online: April 3, 2013

\section{Endothelial Junction Regulation: A Prerequisite for Leukocytes Crossing the Vessel Wall}

\author{
Anna E. Daniel Jaap D. van Buul \\ Department of Molecular Cell Biology, Sanquin Research and Landsteiner Laboratory, Academic Medical Center, \\ University of Amsterdam, Amsterdam, The Netherlands
}

\section{Key Words}

Vascular endothelial cadherin - Cell-cell junctions .

Signaling · Extravasation · Diapedesis · Transmigration

\begin{abstract}
The leukocytes of the innate immune system, especially neutrophils and monocytes, exit the circulation early in the response to local inflammation and infection. This is necessary to control and prevent the spread of infections before an adaptive immune response can be raised. The endothelial cells and the intercellular junctions that connect them form a barrier that leukocytes need to pass in order to get to the site of inflammation. The junctions are tightly regulated which ensures that leukocytes only exit when and where they are needed. This regulation is disturbed in many chronic inflammatory diseases which are characterized by ongoing recruitment and interstitial accumulation of leukocytes. In this review, we summarize the molecular mechanisms that regulate endothelial cell-cell junctions and prevent or permit leukocyte transendothelial migration.
\end{abstract}

Copyright $\odot 2013$ S. Karger AG, Basel

\section{KARGER}

(c) 2013 S. Karger AG, Basel

$1662-811 \mathrm{X} / 13 / 0054-0324 \$ 38.00 / 0$

E-Mail karger@karger.com

www.karger.com/jin

\section{Introduction}

Endothelial cells are a specialized cell type that lines the inner lumen of all blood and lymph vessels. They are at the interface between blood and surrounding tissues. The cell-cell contacts between endothelial cells are highly regulated and determine permeability to cells (leukocytes, red blood cells), macromolecules (hormones, cytokines), nutrients (amino acids, sugars) and solutes (ions). They also form a barrier to blood-borne infectious agents.

Endothelia are heterogeneous both in function and structure, depending on the vessel type (arterial vs. venous), size (macrovasculature vs. microvasculature) and the organ of origin (e.g., central nervous system vs. lymphoid organs) [1]. On the one hand, the endothelial barrier can be very stringent. This is the case in the central nervous system where endothelial cells together with surrounding pericytes and glial cells form the blood-brain barrier. The blood-brain barrier limits the entry of immune cells and immune surveillance of the central nervous system and, at the same time, the entry of microorganisms and susceptibility to microbial infections [2]. On the other hand, the endothelial barrier can be very per-

Dr. Jaap D. van Buul

Department of Molecular Cell Biology, Sanquin Research and Landsteiner Laboratory Room U019, Academic Medical Center, University of Amsterdam

Plesmanlaan 125, NL-1066CX Amsterdam (The Netherlands)

E-Mail j.vanbuul@ sanquin.nl 


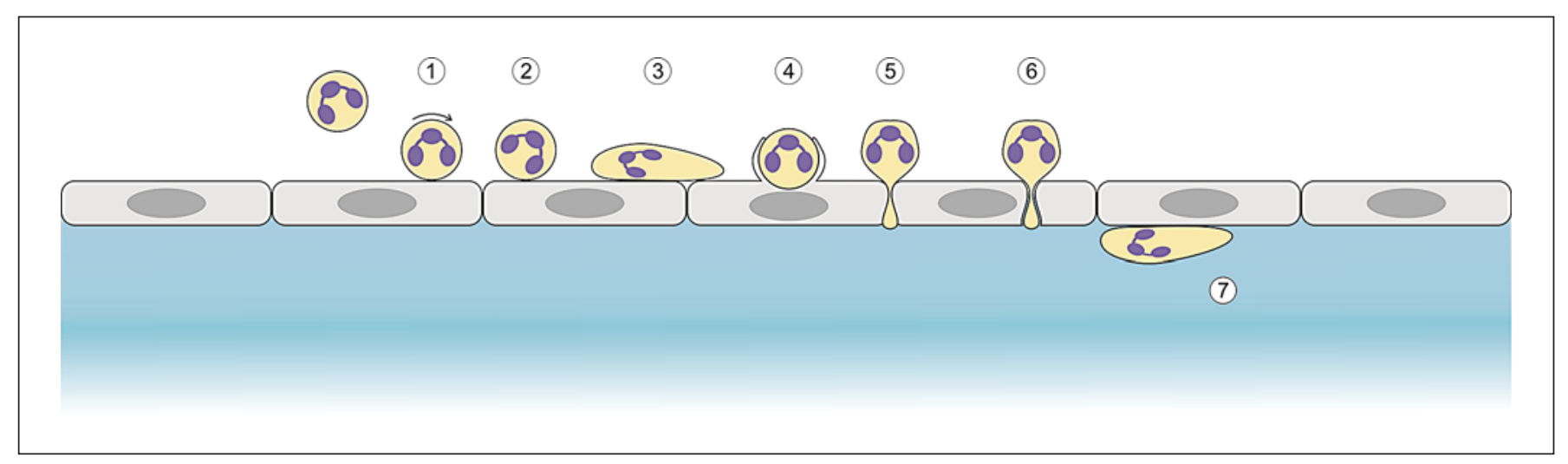

Fig. 1. Leukocyte adhesion and transmigration cascade. Leukocytes from the blood stream roll on selectins expressed by endothelia at sites of inflammation (1). Activation through cytokines deposited on endothelial cells leads to activation of leukocyte integrins and firm adhesion to ICAM-1 or VCAM-1 (2). Adhered leukocytes then crawl along chemotactic gradients on endothelial cells (3). Interaction with the endothelial cell, especially through ICAM-1 and VCAM-1, leads to the formation of docking structures (4) and signaling events that destabilize endothelial cell junctions and induce transmigration through endothelial cell junctions (paracellular) (5) or through the cell body (transcellular) (6). Transmigrated leukocytes can then crawl in the subendothelial space and enter the perivascular tissues (7). missive to leukocytes, as is the case in high endothelial venules of secondary lymphoid organs where lymphocytes constitutively exit the blood stream [3]. These examples are extreme cases in a spectrum of endothelial barrier properties, and the majority of vessel types fall in between these two extremes.

Under physiological conditions, endothelia in the arterial branch of the vascular system are characterized by low permeability to solutes and leukocytes, compared to those in the venous branch where the endothelial cells are thinner and where leukocytes can exit the circulation more easily [4]. In response to local inflammation, the permeability to small and large molecules as well as to immune cells is greatly increased, particularly in postcapillary venules $[1$, 5]. The tight regulation of the endothelial cell barrier both under physiological and inflammatory conditions is crucial. It can have detrimental effects on human health when the regulatory mechanisms are disturbed. These range from exposure of subendothelial extracellular matrix and consequent thrombus formation to overshooting inflammation caused by the constitutive influx of leukocytes, as is the case in many autoimmune and other chronic inflammatory diseases such as rheumatoid arthritis [6].

\section{Transendothelial Migration}

A key event in the initiation of inflammation is the migration of immune cells out of blood vessels and into inflamed tissues. For this, leukocytes must cross a layer of endothelial cells in a process called 'transendothelial migration', transmigration, diapedesis or extravasation. On their way out of blood vessels, leukocytes essentially take one of two routes: (1) the paracellular route between endothelial cells, i.e. through the adhesion molecules that form the endothelial cell-cell junctions, or (2) the transcellular route through the body of endothelial cells which leaves the junctions intact (fig. 1). The proportion of either of the routes taken varies depending on the type of endothelial cells (micro- vs. macrovascular) and leukocytes (monocytes, neutrophils, lymphocytes) used in experiments and on whether experiments were performed with endothelial cell lines or in vivo [for a review, see ref. $7,8]$. The initial belief was that most leukocytes use the paracellular route for transmigration. However, due to difficulties that arise from observing transcellular migration events, this type of migration may have been largely underestimated in earlier studies: for one, in human umbilical vein endothelial cells, the most commonly used endothelial cell line, transcellular migration, only made up $5-10 \%$ of transmigration events, whereas with other endothelial cell lines, up to $40 \%$ of leukocytes used the transcellular route [7]. Further, the majority of transcellular migration events occur in close proximity to endothelial cell junctions where they can easily be mistaken for paracellular migration when light microscopic methods are used. Only in painstakingly undertaken studies using serial-section electron microscopy was it possible to differentiate unambiguously between transcellular and paracellular transmigration at perijunctional sites [9-12]. 
The two modes of endothelial transmigration are nonredundant and may serve different functions, as blocking one pathway does not augment the other [13]. While the exact functions and benefits of either route are still under debate, Lossinsky and Shivers [14] hypothesize that the transcellular route may be preferred as the 'route of least resistance' in endothelial beds with extended intercellular junctional complexes, e.g., the microvascular endothelia of the blood-brain barrier. Transcellular migration leaves the intercellular junctions intact and ensures specific and regulated extravasation of leukocytes. For example, the transcellular route was used exclusively by leukocytes in experimental autoimmune encephalomyelitis, a mouse model of multiple sclerosis [15-17]. The exact regulatory mechanisms, the proportion and the function of this mode of transmigration remain to be clarified. In keeping with the scope of this review, we will go on to discuss the mechanisms underlying paracellular migration. The reader is referred to the following publications for a thorough review of transcellular transendothelial migration $[7,8]$.

The process of transendothelial migration is initiated by perivascular mast cells that produce proinflammatory mediators, like tumor necrosis factor- $\alpha$ (TNF- $\alpha$ ) or interleukin-1 $\beta$, in response to an infection or tissue damage. Proinflammatory mediators induce signaling pathways in endothelial cells that cause an increase in vascular permeability for molecules and leukocytes [18]. Of equal importance, these mediators also trigger endothelial cells to express adhesion molecules, especially selectins and the integrin ligands intracellular cell adhesion molecule 1 (ICAM-1) and vascular endothelial cell adhesion molecule 1 (VCAM-1). Circulating leukocytes express integrins and other ligands for the recognition of and adhesion to inflamed endothelia. In a multistep process that includes a sequence of low- and high-affinity interactions of leukocytes with endothelial cells, followed by crawling on the luminal surface of vessels, leukocytes can ultimately migrate through the vessel wall (fig. 1) [19]. What ultimately determines where leukocytes transmigrate has not been conclusively clarified. It was suggested in an earlier study that neutrophils preferred tricellular corners where endothelial junctions are discontinuous [20]. In a recent study, it was shown that chemokines are released from endothelial vesicles at sites of contact with certain sets of effector T lymphocytes. These vesicles marked 'hot spots' where these $\mathrm{T}$ lymphocytes preferentially transmigrated [21]. Whether other types of leukocytes use similar chemokine hot spots remains to be clarified.

The first wave of immune cells that enter a site of inflammation are neutrophils, followed by monocytes and later lymphocytes [22]. Together, the neutrophils and monocytes engulf microorganisms and damaged tissue by phagocytosis and keep infection in check until an antigen-specific adaptive immune response can be mounted. They also release cytokines that attract further leukocytes to the site of inflammation. The influx of new leukocytes from the bloodstream to sites of inflammation is one of the early check points in this process and therefore of particular importance. In many chronic inflammatory diseases, the endothelial barrier is disturbed and a large number of leukocytes can accumulate and damage the surrounding tissues. One such example is rheumatoid arthritis, an autoimmune disease that affects one or several joints. In rheumatoid arthritis, adhesion molecules, especially selectins, are upregulated on blood vessels of the synovial membrane of joints. This in combination with the local release of inflammatory chemokines such as CXCL5 or CCL2 leads to a massive influx of leukocytes into the synovial cleft and ultimately to severe damage to the joint [23].

In summary, transendothelial migration is a complex multistep process in which leukocytes need to overcome several barriers including the endothelial cell layer in order to get to sites of inflammation. In the following, we will describe the barriers imposed by endothelial cell-cell junctions and how they are regulated, especially during transmigration.

\section{Endothelial Cell-Cell Junctions}

Endothelial cell-cell junctions connect neighboring cells at their lateral borders. The junctions present one of the main obstacles that leukocytes encounter on their way out of blood vessels. They act as a gateway for transmigrating leukocytes and a primary point for the regulation of transmigration. On a molecular level, the junctions are formed by the multi-protein complexes of the lateral border recycling compartment (LBRC), tight junctions and adherens junctions (fig. 2).

\section{Lateral Border Recycling Compartment}

The LBRC is a specialized membranous organelle that is located in close vicinity to endothelial cell-cell junctions. Associated with it are the endothelial adhesion molecules platelet/endothelial cell adhesion molecule 1 (PECAM-1) and CD99 which form homophilic adhesions between endothelial cells [24]. Through the LBRC, PECAM-1 and CD99 are transported to either the apical or lateral cell surface where they are available for interac- 
Fig. 2. The three multiprotein complexes that form endothelial cell-cell junctions (not drawn to scale). (1) Endothelial adherens junctions consisting of VE-cadherin which associates with intracellular p120catenin and $\beta$-catenin ( $\beta$-cat) and protein tyrosine phosphatases, like SHP2, and kinases (not shown). (2) Tight junctions are composed of occludin, claudins (claudin-5 is endothelial specific but other claudins are also expressed) and JAM-A, JAM-B and JAM-C. On the cytoplasmic side, tight junction proteins are associated with proteins like ZO-1 and indirectly with the cytoskeleton. (3) The lateral border recycling compartment with PECAM-1 and CD99 (JAM-A can also be found in the lateral border recycling compartment) underlies the adjoining cell membranes and transports the proteins from the abluminal to the apical and lateral sides where the proteins can interact with proteins on adjacent cells or form contacts with transmigrating cells.

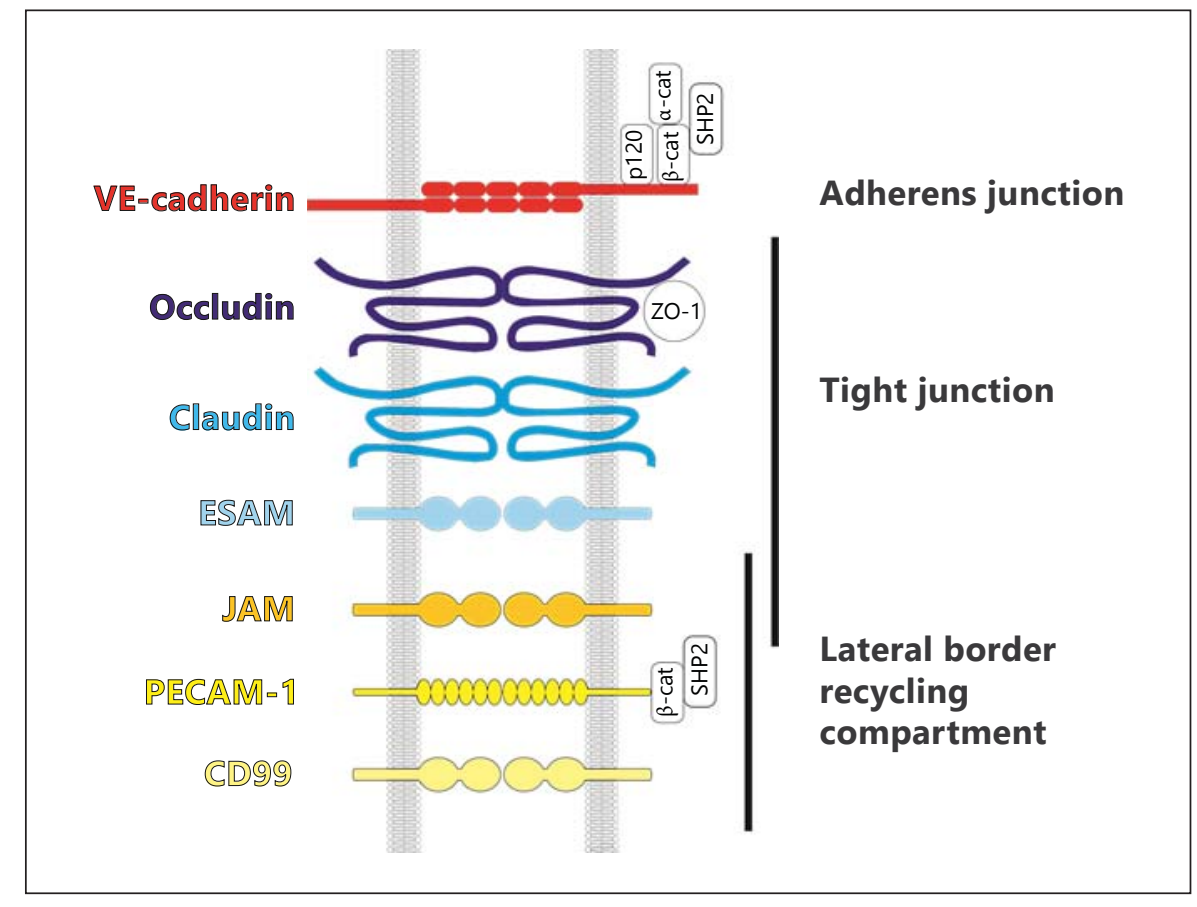

tions with their homophilic ligands on leukocytes. PECAM-1 and CD99 contribute to trans- and paracellular modes of migration, respectively [25]. Furthermore, when endothelial PECAM-1 is blocked, leukocytes can adhere and crawl on the luminal surface of blood vessels but cannot transmigrate [26]. When CD99 is blocked, leukocytes can start to move through the endothelial junctions but then 'get stuck' and cannot complete transmigration [27, 28], suggesting that the two proteins act in sequence to expedite diapedesis. The role of the LBRC during transmigration is to shuttle PECAM-1 and CD99 back to the apical side of endothelial cells where they are then available for further transmigration events. This makes the LBRC and the proteins associated with it indispensable for efficient transendothelial migration.

\section{Endothelial Tight Junctions}

Tight junctions form belts of adhesion molecules at the lateral border of endothelial cells where their main function is to control paracellular diffusion of small molecules [2]. Endothelial tight junctions are composed of the integral transmembrane proteins occludin, members of the claudin family, particularly the endothelium-specific claudin-5 [29], endothelial cell-selective adhesion molecule (ESAM) [30] and the junctional adhesion molecules (JAMs) A, B and C [31]. The variations in the barrier properties of endothelia in different vascular beds corre- late with the abundance and complexity of endothelial tight junctions [32]: in transmission electron microscopy, the tight junctions of postcapillary venules present as punctate, electron-dense regions whereas the junctions of arterial endothelia and the blood-brain barrier are more extended and show high expression of occludin $[4,33$, 34]. In the brain these observations coincide with the immune surveillance being 100 times lower compared to that in the spleen or in lungs [35].

ESAM molecules form homophilic contacts between endothelial cells. Of interest, a role for ESAM in opening endothelial junctions was inferred from studies showing that neutrophil transmigration was reduced in $\mathrm{ESAM}^{-/-}$ mice $[36,37]$. Moreover, monocyte adhesion and migration into atherosclerotic plaques was impaired in mice deficient for apolipoprotein E and ESAM [38]. It was suggested that ESAM contributed to the loosening of junctions by forming a platform for molecules that recruit and activate RhoA [39]. As we describe below, RhoA activation in endothelial cells can lead to the disruption of endothelial cell junctions, and thus, facilitate leukocyte extravasation. It remains unclear whether leukocytes can directly target ESAM-dependent junctions and destabilize them in order to transmigrate.

JAMs, as a part of tight junctions, mediate hetero- and homophilic interactions with JAMs on neighboring cells. JAMs are expressed on epithelial and endothelial cells in 
many different organs [40] and are important for the formation of tight junctions and the establishment of the vascular diffusion barrier. Furthermore, JAM-A, JAM-B and JAM-C can bind to the leukocyte integrins LFA-1, VLA-4 and Mac-1, respectively [41-43]. JAMs, especially JAM-A which can also be found in the LBRC [25], are important for transendothelial migration of leukocytes and are upregulated in many inflammatory conditions [40]. The importance of JAM-A for transmigration is underlined by experiments that showed when JAM-A was blocked with monoclonal antibodies, transendothelial migration was decreased [41]. Further, a modified soluble form of JAM-A, which interferes with JAM-A LFA-1 interactions but does not affect homophilic JAM-A interactions, inhibits leukocyte recruitment to sites of inflammation [44].

Chavakis et al. [42] performed experiments in which injection of soluble JAM-C prior to intraperitoneal injection of thioglycollate significantly decreased the number of neutrophils in peritoneal lavage fluid. The authors of this study attributed the reduction in extravasated leukocytes to JAM-C being necessary for luminal to abluminal migration. An alternative explanation was offered by Imhof and colleagues [45] who used live-cell imaging to track monocytes during transmigration on TNF- $a-$ stimulated human umbilical vein endothelial cell monolayers. These studies revealed that after the addition of soluble JAM-C, the number of transmigrated monocytes was initially the same as in control conditions, but that about $25 \%$ of the transmigrated monocytes moved back to the luminal side of the endothelial monolayer [45]. These findings were further corroborated by an in vivo study in which either JAM-C blocking antibodies or lowered JAM-C expression as a consequence of ischemia/reperfusion result in increased reverse transmigration of neutrophils from the abluminal to the luminal side of vessels. Overall, total number of transmigrated neutrophils compared to controls was reduced in those experiments [46]. This indicates that JAM-C ensures unidirectional migration possibly by acting as a 'valve' that permits the transmigration out of vessels but restricts the natural propensity of leukocytes for reverse transmigration. This mechanism may be of particular importance to ensure polarized migration into lymph nodes in high endothelial venules, where leukocytes constitutively exit the circulation and where JAM-C is highly expressed [47].

In summary, tight junctions have an important role for the maintenance of junctional integrity and the permeability barrier formed by endothelial cell-cell junctions. Independent of their roles in the tight junctional complex, some components of tight junctions like ESAM and JAMs play an active role in promoting leukocyte diapedesis.

\section{Endothelial Adherens Junctions}

Adherens junctions, like tight junctions, mediate endothelial cell-cell adhesion. Endothelial adherens junctions are formed by vascular endothelial (VE) cadherin which regulates paracellular permeability to macromolecules $[48,49]$. Further, the importance of VE-cadherin for transendothelial migration was demonstrated in mice: intravenous administration of antibodies that block VE-cadherin homophilic interactions lead to increased vascular permeability in the heart and lung and to the accumulation of neutrophils in inflamed peritoneum [50,51].

Structurally, VE-cadherin is a classical cadherin with an extracellular domain that mediates $\mathrm{Ca}^{2+}$-dependent homophilic adhesion, a transmembrane region and a conserved cytoplasmic tail. The cytoplasmic domain interacts directly with p120-catenin and $\beta$ - or $\gamma$-catenin, a reciprocally exclusive interaction. VE-cadherin is also associated with $\alpha$-catenin, the cytoskeleton and other signaling molecules [52]. The formation of the cadherincatenin complex is necessary for VE-cadherin expression on the cell surface. Especially the interaction with p120catenin prevents internalization and degradation of VEcadherin [53], and silencing of p120-catenin leads to decreased expression of VE-cadherin and $\alpha-, \beta$ - and $\gamma$-catenin and a drop in transendothelial electrical resistance [54]. Similarly, in epithelial cells, $\beta$-catenin ensures the expression of E-cadherin at the plasma membrane by preventing the ubiquitination and degradation of E-cadherin [55]. However, the long-standing assumption that $\beta$-catenin directly links E- and VE-cadherin to $\alpha$-catenin and thus to the actin cytoskeleton has come under debate since the labs of Nelson and colleagues $[56,57]$ demonstrated in biochemical experiments that $\alpha$-catenin cannot bind to $\beta$-catenin and actin simultaneously. Even though the role of $\alpha$-catenin in this context has not been conclusively clarified, there is ample evidence for the connection of cadherins with the actin cytoskeleton through other actin-binding molecules [58]. The presence of a-catenin in the cadherin-catenin complex is nonetheless integral to the stability and function of VE-cadherin-mediated adherens junctions. This is underlined by findings from Schulte et al. [13] who designed a chimeric protein comprising the extracellular and transmembrane parts of VE-cadherin fused to the C-terminal part of $\alpha$-catenin. Expression of this chimera prevents the vascular endothelial growth factor (VEGF)- or histamine-induced perme- 
ability increase in mouse skin. Further, leukocyte adhesion remained unaltered, whereas transmigration was blocked and leukocyte recruitment to inflamed lung or skin tissues was greatly decreased.

Taken together, VE-cadherin and the associated catenins are of crucial importance to the formation and stability of adherens junctions, and thus, to the regulation of leukocyte transmigration. In the following, we will describe mechanisms by which endothelial cells modify junction proteins and therefore allow or restrict leukocyte movements across endothelia.

\section{Regulation of Endothelial Junctions}

Endothelial junctions are tightly regulated which ensures adequate barrier function under physiological conditions. The junctions are also amenable to rapid adjustments during inflammation without disrupting the gross integrity of endothelial cell layers but allowing the influx of immune cells. Inflammatory stimuli like TNF- $\alpha$, interleukin- $1 \beta$ or interferon- $\gamma$, but also engagement of integrin ligands, increase endothelial permeability to molecules and leukocytes. This requires signaling pathways that trigger the remodeling of endothelial cell-cell junctions and enable leukocyte extravasation.

\section{Metalloproteinases}

A mechanism that is often omitted from reviews on transendothelial migration is the exodomain shedding of adhesion molecules that form the endothelial barrier, particularly VE-cadherin, by matrix metalloproteinases (MMPs) or ADAMs (a disintegrin and metalloproteinase). This is surprising considering that elevated levels of soluble VE-cadherin, corresponding to a $90-\mathrm{kDa}$ extracellular fragment of VE-cadherin, correlate with disease activity of rheumatoid arthritis, diabetic retinopathy and coronary atherosclerosis, all conditions characterized by chronic infiltration with inflammatory cells [59-61]. Both types of enzymes are produced by leukocytes and endothelial cells alike. Of the MMPs, in particular MMP2 and MMP-7 have been shown to cleave the extracellular domain of VE-cadherin, e.g., in response to TNF- $\alpha[22$, $61,62]$. However, a direct connection between VE-cadherin shedding by MMPs and leukocyte transmigration has not yet been shown.

Like MMPs, the enzymes of the ADAM family are also upregulated in response to inflammatory mediators. Several lines of evidence suggest that ADAM-mediated VEcadherin shedding may facilitate leukocyte transmigra-

Leukocyte Transendothelial Migration tion. Pharmacological inhibition of ADAM10 reduces VE-cadherin shedding and monocyte migration [63]. By a similar mechanism, the inhibition or knockdown of ADAM10 in either endothelial cells or leukocytes blocks the transmigration of $\mathrm{T}$ lymphocytes [64], and finally, knockdown of ADAM15 in endothelial cells reduces neutrophil migration $[65,66]$. These results demonstrate that in the absence of ADAM activity, the number of migrating leukocytes is reduced, whereas when ADAM expression is upregulated in response to inflammatory mediators, one may speculate that diapedesis would be promoted. It is interesting to note that both ADAM10 and ADAM17 can shed JAM-A, which results in an overall decrease in leukocyte transmigration. This may be due to the shed JAM-A exodomains blocking the binding sites for LFA-1 on leukocytes [67]. The role of ADAMs in vascular biology is more extensively reviewed in Dreymueller et al. [68].

In summary, especially the ADAM-type metalloproteinases affect transmigration. By shedding VE-cadherin exodomains, ADAMs can open the cell-cell junctions for diapedesis, whereas by shedding JAM-A exodomains, endothelium-leukocyte interactions are blocked and diapedesis inhibited. The exact regulation and coordination of these events requires further study and many questions remain unanswered. It will be interesting to know how exodomain shedding affects the stability of the cadherincatenin complex. More important still is the question whether the VE-cadherin exodomain shedding that can be observed in some inflammatory diseases occurs as a prerequisite for or as a consequence of transmigration. In the former case, metalloproteinases could be essential for the initiation, and in the latter case, for the perpetuation of an inflammatory infiltrate into tissues. Metalloproteinase inhibitors are already used in the therapy of cancer but may also be valuable new targets for therapeutic intervention in inflammatory diseases.

\section{Protein Tyrosine Kinases and Phosphatases}

Tyrosine phosphorylation is a mechanism often employed to bring about rapid changes in protein interactions. Of the proteins in endothelial cell-cell junctions, VE-cadherin especially is a target for tyrosine phosphorylation $[69,70]$. There are nine tyrosine residues in the cytoplasmic tail of VE-cadherin. In particular, phosphorylation of tyrosine residues Y658 and Y731 is associated with increased endothelial permeability and facilitates transendothelial migration. When these residues are phosphorylated, p120- and $\beta$-catenin, respectively, can no longer interact with VE-cadherin, which leads to the 
dissociation and internalization of the cadherin-catenin complex [71]. Conversely, overexpression and binding of p120-catenin to VE-cadherin contributes to junctional stability by preventing the phosphorylation of VE-cadherin on Y658 and, at the same time, inhibits diapedesis of neutrophils $[72,73]$.

Among the stimuli that induce tyrosine phosphorylation in endothelial cells are histamine, thrombin, plateletactivating factor, VEGF and TNF- $\alpha$ [74-76]. Similarly, ICAM-1 crosslinking with antibody-coated beads or integrin-mediated leukocyte adhesion lead to the recruitment and activation of the tyrosine kinases Src and Pyk2 at sites of adhesion and concomitant phosphorylation of VE-cadherin [77-79]. In the same studies, leukocyte transmigration was prevented when non-phosphorylatable VE-cadherin mutants were expressed in endothelial cells $[77,79]$. These findings indicate that tyrosine phosphorylation of endothelial junction proteins is indispensable for effective leukocyte transmigration. There have been some reports on serine and threonine phosphorylation in response to VEGF which lead to the internalization of VE-cadherin and increased endothelial permeability [80]. Whether serine/threonine phosphorylation events are also employed to facilitate leukocyte transmigration is not yet clear.

In a recent study, in which both in vivo and in vitro endothelial cell systems were used, the low shear stress typical for venous vessels was identified as a regulator of VE-cadherin phosphorylation status [81]: in veins, VEcadherin is constitutively phosphorylated on tyrosine residues Y658 and Y685, whereas in arterial-type vessels, VE-cadherin remains largely unphosphorylated on those residues. Further, application of arterial flow to veins, by introducing a shunt from the carotid artery to the jugular vein, decreased the phosphorylation of Y658 and Y685. The authors show that venous shear stress activates Srcmediated VE-cadherin phosphorylation which leaves the endothelial barrier function intact but makes the endothelial cells more susceptible for rapid opening of junctions in response to inflammatory mediators.

The actions of protein kinases are held in check by protein tyrosine phosphatases (PTPs). Phosphatases counteract the action of tyrosine kinases and may thus stabilize junctions by dephosphorylating VE-cadherin and the catenins. In endothelial cells, density-enhanced phosphatase 1, VE receptor-type PTP, РTP $\mu$, PTP1B and Src-homology 2 domain containing phosphatase 2 (SHP2) have been described. The best-studied example is VE-PTP which localizes to the junctions of confluent endothelial cells and dissociates from VE-cadherin in response to
VEGF or when neutrophils or T lymphocytes extravasate $[82,83]$. More recently, SHP2 has been described to stabilize VE-cadherin in response to endothelial fibroblast growth factor [84] and to aid the recovery of VE-cadherin-mediated junctions after thrombin treatment [85]. More research is required to clarify if SHP2 inhibition could facilitate transmigration. Overall, the balance of phosphorylation and dephosphorylation of VE-cadherin determines the stability of endothelial cell junctions and whether or not leukocytes can transmigrate.

\section{Shear Stress}

Endothelial cells experience shear stress caused by blood flow. Shear stress can be sensed and translated into intracellular signals by mechanosensing complexes, including ion channels, the glycocalyx and a mechanosensory complex consisting of VEGF receptor 2 and the junctional proteins VE-cadherin and PECAM-1 [86, 87]. Shear stress is both an impediment and a necessity for efficient transmigration. On the one hand leukocytes in the circulation need to slow down sufficiently before they can cross the vessel wall. For this, they engage in low-affinity adhesive interactions with selectins that cause rolling adhesion of leukocytes on the endothelium (fig. 1) [88]. On the other hand selectin-mediated adhesion requires at least low levels of shear stress for efficient binding to selectin ligands [89]. Shear stress also enhances transendothelial migration of Tlymphocytes on endothelia coated with chemokines, whereas chemokines alone only support luminal crawling [90]. Another way in which shear stress affects leukocyte transmigration is by altering gene expression. Especially, disturbed or turbulent flow can induce the expression of inflammatory genes including the adhesion molecules ICAM-1 and VCAM-1 [91]. Vascular inflammation in response to disturbed flow at vascular bifurcations has been studied extensively in the context of atherosclerosis which is characterized by the accumulation of macrophages in the vessel wall [92].

While there is no doubt that shear stress is necessary for efficient transcellular migration, to date, there have been no studies that directly correlate junctional stability and transmigration, on the one hand, with shear stress on the other hand. Nonetheless, there are several studies that implicate disturbed flow and low shear stress with increased junctional permeability and instability, and vice versa. As we have discussed above, low levels of shear stress lead to increased phosphorylation of VE-cadherin and more leakage through junctions [81]. In vivo, and in vitro when endothelial cells are subjected to high laminar 
shear stress, the cells align in the direction of flow $[87,93$, 94]. VE-cadherin-based junctions that lie in parallel to the direction of flow are linear and, presumably, more stable compared to the junctions that are perpendicular to flow and have a 'jagged' phenotype $[93,94]$. The latter is reminiscent of the less stable focal adherens junctions in which vinculin, another mechanosensor, colocalizes with VE-cadherin [95]. With the new methods for intravital imaging, it will be possible to investigate whether transendothelial migration happens preferentially at the jagged junctions or at junctions that are phosphorylated and may thus provide the missing link between shear stress, junctional stability and transmigration.

\section{Small GTPases}

The actin cytoskeleton is an important mediator of endothelial cell-cell junctions. Small GTPases, as key regulators of the actin cytoskeleton, are involved in the formation and maintenance of cell-cell junctions [96]. The Rho family GTPases RhoA and Racl and the Ras family GTPase Rap 1 have been shown to control endothelial junction stability and will be discussed in the following.

The activity of Rho GTPases is regulated by guaninenucleotide exchange factors (GEFs) that enhance the exchange of GDP for GTP. The GTP-bound active form of the GTPases interacts with effector molecules which regulates their activity and localization within the cell. The signaling by Rho GTPases is attenuated by GTPase-activating proteins, which catalyze the intrinsic GTP hydrolyzing activity of the GTPases and transfers them to the GDP-bound inactive state [97]. GEFs and GTPase-activating proteins not only affect the activation state, but also the localization and timing of GTPase activity. Overall, an intricate balance of GEF-induced GTPase activation and GAP-mediated deactivation needs to be maintained to ensure that cells function properly.

The function of the Rho GTPases RhoA and Rac1 in epithelial cells has been studied in great detail. They play an important role in regulating E-cadherin-mediated junction formation and maintenance [98]. Yamada and Nelson [99] have described that during initial cell-cell contact formation, newly forming E-cadherin-based adhesion sites are surrounded by areas of localized Racl activation that help expand the contact zones. Simultaneously, local activation of RhoA was observed adjacent to but not overlapping with areas where Racl was activated. These specific, localized activities are in line with studies suggesting that Racl and RhoA are inversely regulated at junctions: recently, Yap and colleagues [100] showed that the Rho-GEF ECT2 binds via $\alpha$-catenin to E-cadherin, which locally activates RhoA, while the concomitant recruitment of MgcRacGAP inactivates Racl. Vice versa, when Racl is activated upon cadherin ligation, cadherinassociated p120-catenin recruits p190RhoGAP which leads to local deactivation of RhoA and overall adherens junction stabilization [101].

In response to inflammatory stimuli, Racl contributes to barrier disruption in endothelial cells: for example, several groups have shown that TNF- $\alpha$ stimulation or VCAM-1 crosslinking on endothelial cells activates Rac1 and induces the generation of reactive oxygen species. Reactive oxygen species in turn inhibit tyrosine phosphatases which results in a net increase in tyrosine phosphorylation of junctional proteins, the destabilization of cellcell junctions and an overall increase in endothelial permeability [102-106]. Further, activation of RhoA and its effector Rho kinase through hypoxia, thrombin or histamine induce the formation of stress fibers, retraction of cell borders and consequently gap formation between cells, junctional destabilization, dispersion of VE-cadherin contacts and a loss of endothelial barrier function [96, 107-109].

During transendothelial migration, endothelial Rho GTPases translate signals from clustered ICAM-1 into intracellular signals. Initially, RhoA is rapidly activated upon ICAM-1 clustering and mediates the formation of F-actin stress fibers and endothelial barrier permeability [110-115]. The small GTPases Rac1 and RhoG are activated at a later stage and control the formation of endothelial docking structures that are involved in leukocyte transmigration [115]. Blocking any one of the three GTPase, RhoA, RhoG or Rac1, perturbs leukocyte passage across the endothelial monolayer. However, whether the reverse is true that GTPases mediate junctional destabilization in order to allow leukocyte passage remains elusive and requires further study.

Finally, the Ras family small GTPase Rap1 plays a role in stabilizing VE-cadherin at junctions. Rap1 activation causes the tightening of adherens junctions [116-118]. Furthermore, the cAMP-Epac1-Rap1 pathway counteracts the thrombin-induced permeability increase by inhibiting RhoA activation [118-121]. On the one hand, inhibition of Rap1-mediated signaling by overexpression of Rap1-GAP or knockdown of Rap1 or its activating GEF, PDZ-GEF, leads to decreased barrier function [117, 122]. Interestingly, Orlova et al. [123] showed that induction of endothelial permeability through VEGF or histamine lead to a recruitment of the tight junction protein JAM-C from the cytosol to cellular junctions where it negatively regulates Rap1 functions. On the other hand, 
JAM-C knockdown improves barrier function by decreasing stress fiber formation and phosphorylation of myosin light chains as well as by activation of Rap1. Conversely, JAM-A activates Rap1 and promotes adherens junction integrity $[124,125]$. In line with these findings, pharmacological activation of Rap1 inhibited transmigration of leukocytes, whereas Rap1 inactivation by overexpression of Rap1 GAP had the opposite effect [126].

As we have described above, there is compelling evidence that GTPase activity regulates essential steps of leukocyte transendothelial migration by inducing actin remodeling and by regulating junction stability and the formation of docking structures that are necessary to assist leukocytes on their route through the vessel wall.

\section{Concluding Remarks}

We have discussed how endothelial cells regulate cellcell junctions in the steady state and during leukocyte transmigration. As a final note, we want to re-emphasize that transmigration is a highly regulated event that requires the active participation of both the transmigrating leukocytes and endothelial cells. It is important to realize that although increased permeability and transmigration often occur at the same time, e.g., in response to an inflammatory stimulus, and share some of the same signaling pathways, they are two distinct events. 'Opening' VEcadherin-mediated junctions with blocking antibodies leads to increased endothelial permeability and leukocyte transmigration [51]. However, when firm adhesion and signaling through ICAM-1 is additionally blocked, fewer leukocytes can transmigrate [127]. This suggests that, even in the absence of flow, leukocytes cannot just 'fall through' open junctions and that the endothelium has functions that go beyond just forming a barrier to leukocyte transmigration. Instead, the endothelial lining of vessels actively enables transmigration, not only by forming a substrate for leukocyte adhesion and crawling but also by providing directional cues in the form of chemokines, by inducing the activation of integrins on leukocytes and by ultimately opening the junctions to transmigrating leukocytes when and where it is necessary. Only through the extensive communication between leukocytes and endothelial cells can the endothelium ensure the regulated and targeted extravasation of specific immune cells.

\section{References}

$\checkmark 1$ Aird WC: Phenotypic heterogeneity of the endothelium. 1. Structure, function, and mechanisms. Circ Res 2007;100:158-173.

$>2$ Wolburg H, Lippoldt A: Tight junctions of the blood-brain barrier: development, composition and regulation. Vascul Pharmacol 2002; 38:323-337.

3 Miyasaka M, Tanaka T: Lymphocyte trafficking across high endothelial venules: dogmas and enigmas. Nat Rev Immunol 2004;4:360 370.

4 Dejana E, Orsenigo F, Molendini C, Baluk P, McDonald DM: Organization and signaling of endothelial cell-to-cell junctions in various regions of the blood and lymphatic vascular trees. Cell Tissue Res 2009;335:17-25.

$>5$ Nagy JA, Benjamin L, Zeng H, Dvorak AM, Dvorak HF: Vascular permeability, vascular hyperpermeability and angiogenesis. Angiogenesis 2008;11:109-119.

6 Nemeth T, Mocsai A: The role of neutrophils in autoimmune diseases. Immunol Lett 2012; 143:9-19.

7 Carman CV, Springer TA: Trans-cellular migration: cell-cell contacts get intimate. Curr Opin Cell Biol 2008;20:533-540.

$>8$ Sage PT, Carman CV: Settings and mechanisms for trans-cellular diapedesis. Front Biosci 2009; 14:5066-5083.
-9 Wolburg H, Wolburg-Buchholz K, Engelhardt $\mathrm{B}$ : Diapedesis of mononuclear cells across cerebral venules during experimental autoimmune encephalomyelitis leaves tight junctions intact. Acta Neuropathol 2005;109:181-190.

10 Feng D, Nagy JA, Pyne K, Dvorak HF, Dvorak AM: Neutrophils emigrate from venules by a transendothelial cell pathway in response to FMLP. J Exp Med 1998;187:903-915.

11 Cho Y, De Bruyn PP: Internal structure of the postcapillary high-endothelial venules of rodent lymph nodes and Peyer's patches and the transendothelial lymphocyte passage. Am J Anat 1986;177:481-490.

12 Azzali G, Arcari ML, Caldara GF: The 'mode' of lymphocyte extravasation through $\mathrm{HEV}$ of Peyer's patches and its role in normal homing and inflammation. Microvasc Res 2008;75: 227-237.

13 Schulte D, Kuppers V, Dartsch N, Broermann A, Li H, Zarbock A, Kamenyeva O, Kiefer F, Khandoga A, Massberg S, Vestweber D: Stabilizing the VE-cadherin-catenin complex blocks leukocyte extravasation and vascular permeability. EMBO J 2011;30:4157-4170.

$>14$ Lossinsky AS, Shivers RR: Structural pathways for macromolecular and cellular transport across the blood-brain barrier during inflammatory conditions. Review. Histol Histopathol 2004;19:535-564.
-15 Raine CS, Cannella B, Duijvestijn AM, Cross $\mathrm{AH}$ : Homing to central nervous system vasculature by antigen-specific lymphocytes. 2 . Lymphocyte/endothelial cell adhesion during the initial stages of autoimmune demyelination. Lab Invest 1990;63:476-489.

16 Lossinsky AS, Badmajew V, Robson JA, Moretz RC, Wisniewski HM: Sites of egress of inflammatory cells and horseradish peroxidase transport across the blood-brain barrier in a murine model of chronic relapsing experimental allergic encephalomyelitis. Acta Neuropathol 1989;78:359-371.

17 Lossinsky AS, Pluta R, Song MJ, Badmajew V, Moretz RC, Wisniewski HM: Mechanisms of inflammatory cell attachment in chronic relapsing experimental allergic encephalomyelitis: a scanning and high-voltage electron microscopic study of the injured mouse blood-brain barrier. Microvasc Res 1991;41: 299-310.

18 Nathan C: Neutrophils and immunity: challenges and opportunities. Nat Rev Immunol 2006;6:173-182.

19 Ley K, Laudanna C, Cybulsky MI, Nourshargh S: Getting to the site of inflammation: the leukocyte adhesion cascade updated. Nat Rev Immunol 2007;7:678-689. 
20 Burns AR, Walker DC, Brown ES, Thurmon LT, Bowden RA, Keese CR, Simon SI, Entman ML, Smith CW: Neutrophil transendothelial migration is independent of tight junctions and occurs preferentially at tricellular corners. J Immunol 1997;159:2893-2903.

-21 Shulman Z, Cohen SJ, Roediger B, Kalchenko V, Jain R, Grabovsky V, Klein E, Shinder V, Stoler-Barak L, Feigelson SW, Meshel T, Nurmi SM, Goldstein I, Hartley O, Gahmberg CG, Etzioni A, Weninger W, Ben-Baruch A, Alon R: Transendothelial migration of lymphocytes mediated by intraendothelial vesicle stores rather than by extracellular chemokine depots. Nat Immunol 2012;13:67-76.

$\checkmark 22$ Luster AD, Alon R, von Andrian UH: Immune cell migration in inflammation: present and future therapeutic targets. Nat Immunol 2005;6:1182-1190.

23 Tarrant TK, Patel DD: Chemokines and leukocyte trafficking in rheumatoid arthritis. Pathophysiology 2006;13:1-14.

24 Mamdouh Z, Chen X, Pierini LM, Maxfield FR, Muller WA: Targeted recycling of PECAM from endothelial surface-connected compartments during diapedesis. Nature 2003;421: 748-753.

25 Mamdouh Z, Mikhailov A, Muller WA: Transcellular migration of leukocytes is mediated by the endothelial lateral border recycling compartment. J Exp Med 2009;206:27952808.

26 Schenkel AR, Chew TW, Muller WA: Platelet endothelial cell adhesion molecule deficiency or blockade significantly reduces leukocyte emigration in a majority of mouse strains. J Immunol 2004;173:6403-6408.

-27 Lou O, Alcaide P, Luscinskas FW, Muller WA: CD99 is a key mediator of the transendothelial migration of neutrophils. J Immunol 2007;178:1136-1143.

-28 Schenkel AR, Mamdouh Z, Chen X, Liebman RM, Muller WA: CD99 plays a major role in the migration of monocytes through endothelial junctions. Nat Immunol 2002;3:143150.

29 Morita K, Sasaki H, Furuse M, Tsukita S: Endothelial claudin: claudin-5/TMVCF constitutes tight junction strands in endothelial cells. J Cell Biol 1999;147:185-194.

- 30 Hirata K, Ishida T, Penta K, Rezaee M, Yang E, Wohlgemuth J, Quertermous T: Cloning of an immunoglobulin family adhesion molecule selectively expressed by endothelial cells. J Biol Chem 2001;276:16223-16231.

- 31 Steed E, Balda MS, Matter K: Dynamics and functions of tight junctions. Trends Cell Biol 2010;20:142-149.

- 32 Wallez Y, Huber P: Endothelial adherens and tight junctions in vascular homeostasis, inflammation and angiogenesis. Biochim Biophys Acta 2008;1778:794-809.

- 33 Hirase T, Staddon JM, Saitou M, Ando-Akatsuka Y, Itoh M, Furuse M, Fujimoto K, Tsukita S, Rubin LL: Occludin as a possible determinant of tight junction permeability in endothelial cells. J Cell Sci 1997;110:1603-1613.
Kevil CG, Okayama N, Trocha SD, Kalogeris TJ, Coe LL, Specian RD, Davis CP, Alexander JS: Expression of Zonula occludens and adherens junctional proteins in human venous and arterial endothelial cells: role of occludin in endothelial solute barriers. Microcirculation 1998;5:197-210.

35 Greenwood J, Heasman SJ, Alvarez JI, Prat A, Lyck R, Engelhardt B: Review: leucocyte-endothelial cell crosstalk at the blood-brain barrier: a prerequisite for successful immune cell entry to the brain. Neuropathol Appl Neurobiol 2011;37:24-39.

36 Khandoga A, Huettinger S, Khandoga AG, Li H, Butz S, Jauch KW, Vestweber D, Krombach F: Leukocyte transmigration in inflamed liver: a role for endothelial cell-selective adhesion molecule. J Hepatol 2009;50:755-765.

- 37 Wegmann F, Petri B, Khandoga AG, Moser C, Khandoga A, Volkery S, Li H, Nasdala I, Brandau O, Fassler R, Butz S, Krombach F, Vestweber D: ESAM supports neutrophil extravasation, activation of Rho, and VEGF-induced vascular permeability. J Exp Med 2006; 203:1671-1677.

38 Inoue M, Ishida T, Yasuda T, Toh R, Hara T, Cangara HM, Rikitake Y, Taira K, Sun L, Kundu RK, Quertermous T, Hirata K: Endothelial cell-selective adhesion molecule modulates atherosclerosis through plaque angiogenesis and monocyte-endothelial interaction. Microvasc Res 2010;80:179-187.

39 Kimura R, Ishida T, Kuriyama M, Hirata K, Hayashi Y: Interaction of endothelial cell-selective adhesion molecule and MAGI-1 promotes mature cell-cell adhesion via activation of RhoA. Genes Cells 2010;15:385-396.

40 Weber C, Fraemohs L, Dejana E: The role of junctional adhesion molecules in vascular inflammation. Nat Rev Immunol 2007;7:467477.

41 Ostermann G, Weber KS, Zernecke A, Schro$\operatorname{der}$ A, Weber C: JAM-1 is a ligand of the beta(2) integrin LFA-1 involved in transendothelial migration of leukocytes. Nat Immunol 2002;3:151-158.

42 Chavakis T, Keiper T, Matz-Westphal R, Hersemeyer K, Sachs UJ, Nawroth PP, Preissner KT, Santoso S: The junctional adhesion molecule-C promotes neutrophil transendothelial migration in vitro and in vivo. J Biol Chem 2004;279:55602-55608.

43 Cunningham SA, Rodriguez JM, Arrate MP, Tran TM, Brock TA: JAM2 interacts with alpha4beta1. Facilitation by JAM3. J Biol Chem 2002;277:27589-27592.

44 Ostermann G, Fraemohs L, Baltus T, Schober A, Lietz M, Zernecke A, Liehn EA, Weber C: Involvement of JAM-A in mononuclear cell recruitment on inflamed or atherosclerotic endothelium: inhibition by soluble JAM-A. Arterioscler Thromb Vasc Biol 2005;25:729_ 735.
45 Bradfield PF, Scheiermann C, Nourshargh S, Ody C, Luscinskas FW, Rainger GE, Nash GB, Miljkovic-Licina M, Aurrand-Lions M, Imhof BA: JAM-C regulates unidirectional monocyte transendothelial migration in inflammation. Blood 2007;110:2545-2555.

- 46 Woodfin A, Voisin MB, Beyrau M, Colom B, Caille D, Diapouli FM, Nash GB, Chavakis T, Albelda SM, Rainger GE, Meda P, Imhof BA, Nourshargh S: The junctional adhesion molecule JAM-C regulates polarized transendothelial migration of neutrophils in vivo. Nat Immunol 2011;12:761-769.

47 Aurrand-Lions M, Johnson-Leger C, Wong C, Du PL, Imhof BA: Heterogeneity of endothelial junctions is reflected by differential expression and specific subcellular localization of the three JAM family members. Blood 2001;98:3699-3707.

48 Lampugnani MG, Resnati M, Raiteri M, Pigott R, Pisacane A, Houen G, Ruco LP, Dejana E: A novel endothelial-specific membrane protein is a marker of cell-cell contacts. J Cell Biol 1992;118:1511-1522.

49 Leach L, Clark P, Lampugnani MG, Arroyo AG, Dejana E, Firth JA: Immunoelectron characterisation of the inter-endothelial junctions of human term placenta. J Cell Sci 1993; 104:1073-1081.

50 Corada M, Mariotti M, Thurston G, Smith K, Kunkel R, Brockhaus M, Lampugnani MG, Martin-Padura I, Stoppacciaro A, Ruco L, McDonald DM, Ward PA, Dejana E: Vascular endothelial-cadherin is an important determinant of microvascular integrity in vivo. Proc Natl Acad Sci USA 1999;96:9815-9820.

51 Gotsch U, Borges E, Bosse R, Boggemeyer E, Simon M, Mossmann H, Vestweber D: VEcadherin antibody accelerates neutrophil recruitment in vivo. J Cell Sci 1997;110:583588 .

52 Dejana E, Orsenigo F, Lampugnani MG: The role of adherens junctions and VE-cadherin in the control of vascular permeability. J Cell Sci 2008;121:2115-2122.

53 Kowalczyk AP, Reynolds AB: Protecting your tail: regulation of cadherin degradation by p120-catenin. Curr Opin Cell Biol 2004;16: 522-527.

54 Herron CR, Lowery AM, Hollister PR, Reynolds AB, Vincent PA: p120 regulates endothelial permeability independently of its $\mathrm{NH} 2$ terminus and Rho binding. Am J Physiol Heart Circ Physiol 2011;300:H36-H48.

55 Hinck L, Nathke IS, Papkoff J, Nelson WJ: Dynamics of cadherin/catenin complex formation: novel protein interactions and pathways of complex assembly. J Cell Biol 1994;125: 1327-1340.

56 Drees F, Pokutta S, Yamada S, Nelson WJ, Weis WI: Alpha-catenin is a molecular switch that binds E-cadherin-beta-catenin and regulates actin-filament assembly. Cell 2005;123: 903-915

57 Yamada S, Pokutta S, Drees F, Weis WI, Nelson WJ: Deconstructing the cadherin-catenin-actin complex. Cell 2005;123:889-901. 
58 Yonemura S: Cadherin-actin interactions at adherens junctions. Curr Opin Cell Biol 2011; 23:515-522.

-59 Navaratna D, McGuire PG, Menicucci G, Das A: Proteolytic degradation of VE-cadherin alters the blood-retinal barrier in diabetes. Diabetes 2007;56:2380-2387.

-60 Soeki T, Tamura Y, Shinohara H, Sakabe K, Onose Y, Fukuda N: Elevated concentration of soluble vascular endothelial cadherin is associated with coronary atherosclerosis. Circ J 2004;68:1-5.

-61 Sidibe A, Mannic T, Arboleas M, Subileau M, Gulino-Debrac D, Bouillet L, Jan M, Vandhuick T, Le Loet X, Vittecoq O, Vilgrain I: Soluble VE-cadherin in rheumatoid arthritis patients correlates with disease activity: evidence for tumor necrosis factor alpha-induced VE-cadherin cleavage. Arthritis Rheum 2012; 64:77-87.

62 Ichikawa Y, Ishikawa T, Momiyama N, Kamiyama M, Sakurada H, Matsuyama R, Hasegawa S, Chishima T, Hamaguchi Y, Fujii S, Saito S, Kubota K, Hasegawa S, Ike H, Oki S, Shimada H: Matrilysin (MMP-7) degrades VE-cadherin and accelerates accumulation of beta-catenin in the nucleus of human umbilical vein endothelial cells. Oncol Rep 2006;15:311-315.

-63 Donners MM, Wolfs IM, Olieslagers S, Mohammadi-Motahhari Z, Tchaikovski V, Heeneman S, van Buul JD, Caolo V, Molin DG, Post MJ, Waltenberger J: A disintegrin and metalloprotease 10 is a novel mediator of vascular endothelial growth factor-induced endothelial cell function in angiogenesis and is associated with atherosclerosis. Arterioscler Thromb Vasc Biol 2010;30:2188-2195.

64 Schulz B, Pruessmeyer J, Maretzky T, Ludwig A, Blobel CP, Saftig P, Reiss K: ADAM10 regulates endothelial permeability and T-cell transmigration by proteolysis of vascular endothelial cadherin. Circ Res 2008;102:1192-1201.

65 Sun C, Wu MH, Lee ES, Yuan SY: A disintegrin and metalloproteinase 15 contributes to atherosclerosis by mediating endothelial barrier dysfunction via Src family kinase activity. Arterioscler Thromb Vasc Biol 2012;32: 2444-2451.

-66 Sun C, Wu MH, Guo M, Day ML, Lee ES, Yuan SY: ADAM15 regulates endothelial permeability and neutrophil migration via Src/ ERK1/2 signalling. Cardiovasc Res 2010;87: 348-355.

-67 Koenen RR, Pruessmeyer J, Soehnlein O, Fraemohs L, Zernecke A, Schwarz N, Reiss K, Sarabi A, Lindbom L, Hackeng TM, Weber C, Ludwig A: Regulated release and functional modulation of junctional adhesion molecule A by disintegrin metalloproteinases. Blood 2009;113:4799-4809.

-68 Dreymueller D, Pruessmeyer J, Groth E, Ludwig A: The role of ADAM-mediated shedding in vascular biology. Eur J Cell Biol 2012;91: $472-485$.
69 Vestweber D, Winderlich M, Cagna G, Nottebaum AF: Cell adhesion dynamics at endothelial junctions: VE-cadherin as a major player. Trends Cell Biol 2009;19:8-15.

70 Timmerman I, Hordijk PL, van Buul JD: Phosphorylation at endothelial cell-cell junctions: implications for VE-cadherin function. Cell Health Cytoskeleton 2010;2:23-31.

71 Potter MD, Barbero S, Cheresh DA: Tyrosine phosphorylation of VE-cadherin prevents binding of p120- and beta-catenin and maintains the cellular mesenchymal state. J Biol Chem 2005;280:31906-31912.

72 Alcaide P, Newton G, Auerbach S, Sehrawat S, Mayadas TN, Golan DE, Yacono P, Vincent P, Kowalczyk A, Luscinskas FW: p120catenin regulates leukocyte transmigration through an effect on VE-cadherin phosphorylation. Blood 2008;112:2770-2779.

73 Alcaide P, Martinelli R, Newton G, Williams MR, Adams A, Vincent PA, Luscinskas FW: p120-catenin prevents neutrophil transmigration independently of RhoA inhibition by impairing Src dependent VE-cadherin phosphorylation. Am J Physiol Cell Physiol 2012; 303:C385-C395.

74 Hudry-Clergeon H, Stengel D, Ninio E, Vilgrain I: Platelet-activating factor increases VE-cadherin tyrosine phosphorylation in mouse endothelial cells and its association with the PtdIns3"-kinase. FASEB J 2005;19: 512-520.

75 Bazzoni G, Dejana E: Endothelial cell-to-cell junctions: molecular organization and role in vascular homeostasis. Physiol Rev 2004;84: 869-901.

76 Angelini DJ, Hyun SW, Grigoryev DN, Garg P, Gong P, Singh IS, Passaniti A, Hasday JD, Goldblum SE: TNF-alpha increases tyrosine phosphorylation of vascular endothelial cadherin and opens the paracellular pathway through fyn activation in human lung endothelia. Am J Physiol Lung Cell Mol Physiol 2006;291:L1232-L1245.

77 Allingham MJ, van Buul JD, Burridge K: ICAM-1-mediated, Src- and Pyk2-dependent vascular endothelial cadherin tyrosine phosphorylation is required for leukocyte transendothelial migration. J Immunol 2007;179: 4053-4063.

78 van Buul JD, Anthony EC, Fernandez-Borja M, Burridge K, Hordijk PL: Proline-rich tyrosine kinase 2 ( $\mathrm{Pyk} 2$ ) mediates vascular endothelial-cadherin-based cell-cell adhesion by regulating beta-catenin tyrosine phosphorylation. J Biol Chem 2005;280:21129-21136.

79 Turowski P, Martinelli R, Crawford R, Wateridge $\mathrm{D}$, Papageorgiou AP, Lampugnani MG, Gamp AC, Vestweber D, Adamson P, Dejana E, Greenwood J: Phosphorylation of vascular endothelial cadherin controls lymphocyte emigration. J Cell Sci 2008;121:29-37.

80 Gavard J, Gutkind JS: VEGF controls endothelial-cell permeability by promoting the beta-arrestin-dependent endocytosis of VEcadherin. Nat Cell Biol 2006;8:1223-1234.
81 Orsenigo F, Giampietro C, Ferrari A, Corada M, Galaup A, Sigismund S, Ristagno G, Maddaluno L, Young KG, Franco D, Kurtcuoglu V, Poulikakos D, Baluk P, McDonald D, Grazia LM, Dejana E: Phosphorylation of VEcadherin is modulated by haemodynamic forces and contributes to the regulation of vascular permeability in vivo. Nat Commun 2012;3:1208.

82 Broermann A, Winderlich M, Block H, Frye M, Rossaint J, Zarbock A, Cagna G, Linnepe R, Schulte D, Nottebaum AF, Vestweber D: Dissociation of VE-PTP from VE-cadherin is required for leukocyte extravasation and for VEGF-induced vascular permeability in vivo. J Exp Med 2011;208:2393-2401.

83 Nottebaum AF, Cagna G, Winderlich M, Gamp AC, Linnepe R, Polaschegg C, Filippova $\mathrm{K}$, Lyck R, Engelhardt B, Kamenyeva O, Bixel MG, Butz S, Vestweber D: VE-PTP maintains the endothelial barrier via plakoglobin and becomes dissociated from VEcadherin by leukocytes and by VEGF. J Exp Med 2008;205:2929-2945.

84 Hatanaka K, Lanahan AA, Murakami M, Simons M: Fibroblast growth factor signaling potentiates VE-cadherin stability at adherens junctions by regulating SHP2. PLoS One 2012;7:e37600.

85 Timmerman I, Hoogenboezem M, Bennett AM, Geerts D, Hordijk PL, van Buul JD: The tyrosine phosphatase SHP2 regulates recovery of endothelial adherens junctions through control of beta-catenin phosphorylation. Mol Biol Cell 2012;23:4212-4225.

-86 Tzima E, Irani-Tehrani M, Kiosses WB, Dejana E, Schultz DA, Engelhardt B, Cao G, DeLisser H, Schwartz MA: A mechanosensory complex that mediates the endothelial cell response to fluid shear stress. Nature 2005;437: 426-431.

87 Tzima E: Role of small GTPases in endothelial cytoskeletal dynamics and the shear stress response. Circ Res 2006;98:176-185.

88 McEver RP, Zhu C: Rolling cell adhesion. Annu Rev Cell Dev Biol 2010;26:363-396.

89 Lawrence MB, Kansas GS, Kunkel EJ, Ley K: Threshold levels of fluid shear promote leukocyte adhesion through selectins (CD62L,P,E). J Cell Biol 1997;136:717-727.

90 Cinamon G, Shinder V, Alon R: Shear forces promote lymphocyte migration across vascular endothelium bearing apical chemokines. Nat Immunol 2001;2:515-522.

-91 Hahn C, Schwartz MA: Mechanotransduction in vascular physiology and atherogenesis. Nat Rev Mol Cell Biol 2009;10:53-62.

92 Malek AM, Alper SL, Izumo S: Hemodynamic shear stress and its role in atherosclerosis. JAMA 1999;282:2035-2042.

93 Rabodzey A, Yao Y, Luscinskas FW, Shaw SK, Dewey CF Jr: Early response of endothelial cells to flow is mediated by VE-cadherin. Cell Commun Adhes 2007;14:195-209. 
$\$ 94$ Miao H, Hu YL, Shiu YT, Yuan S, Zhao Y, Kaunas R, Wang Y, Jin G, Usami S, Chien S: Effects of flow patterns on the localization and expression of VE-cadherin at vascular endothelial cell junctions: in vivo and in vitro investigations. J Vasc Res 2005;42:77-89.

95 Huveneers S, Oldenburg J, Spanjaard E, van der Krogt G, Grigoriev I, Akhmanova A, Rehmann H, de Rooij J: Vinculin associates with endothelial VE-cadherin junctions to control force-dependent remodeling. J Cell Biol 2012;196:641-652.

96 Beckers CM, van Hinsbergh VW, van Nieuw Amerongen GP: Driving Rho GTPase activity in endothelial cells regulates barrier integrity. Thromb Haemost 2010;103:40-55.

$\$ 97$ Jaffe AB, Hall A: Rho GTPases: biochemistry and biology. Annu Rev Cell Dev Biol 2005; 21:247-269.

$\$ 98$ Menke A, Giehl K: Regulation of adherens junctions by Rho GTPases and p120catenin. Arch Biochem Biophys 2012;524: 48-55.

99 Yamada S, Nelson WJ: Localized zones of Rho and Rac activities drive initiation and expansion of epithelial cell-cell adhesion. J Cell Biol 2007;178:517-527.

100 Ratheesh A, Gomez GA, Priya R, Verma S, Kovacs EM, Jiang K, Brown NH, Akhmanova A, Stehbens SJ, Yap AS: Centralspindlin and alpha-catenin regulate Rho signalling at the epithelial zonula adherens. Nat Cell Biol 2012;14:818-828.

101 Wildenberg GA, Dohn MR, Carnahan RH, Davis MA, Lobdell NA, Settleman J, Reynolds AB: p120-catenin and p190RhoGAP regulate cell-cell adhesion by coordinating antagonism between Rac and Rho. Cell 2006;127:1027-1039.

102 Deem TL, Abdala-Valencia H, Cook-Mills JM: VCAM-1 activation of endothelial cell protein tyrosine phosphatase $1 \mathrm{~B}$. J Immunol 2007;178:3865-3873.

103 Cook-Mills JM, Johnson JD, Deem TL, Ochi A, Wang L, Zheng Y: Calcium mobilization and Racl activation are required for VCAM1 (vascular cell adhesion molecule-1) stimulation of NADPH oxidase activity. Biochem J 2004;378:539-547.

104 Cain RJ, Vanhaesebroeck B, Ridley AJ: The PI3K p110alpha isoform regulates endothelial adherens junctions via Pyk2 and Rac1. J Cell Biol 2010;188:863-876.

105 Monaghan-Benson E, Burridge K: The regulation of vascular endothelial growth factorinduced microvascular permeability requires Rac and reactive oxygen species. J Biol Chem 2009;284:25602-25611.

106 van Wetering S, van den Berk N, van Buul JD, Mul FP, Lommerse I, Mous R, ten Klooster JP, Zwaginga JJ, Hordijk PL: VCAM1-mediated Rac signaling controls endothelial cell-cell contacts and leukocyte transmigration. Am J Physiol Cell Physiol 2003; 285:C343-C352.
107 Wojciak-Stothard B, Potempa S, Eichholtz T, Ridley AJ: Rho and Rac but not Cdc42 regulate endothelial cell permeability. J Cell Sci 2001;114:1343-1355.

108 Warfel JM, D’Agnillo F: Anthrax lethal toxin-mediated disruption of endothelial VEcadherin is attenuated by inhibition of the Rho-associated kinase pathway. Toxins (Basel) 2011;3:1278-1293.

109 Wojciak-Stothard B, Tsang LY, Haworth SG: Rac and Rho play opposing roles in the regulation of hypoxia/reoxygenation-induced permeability changes in pulmonary artery endothelial cells. Am J Physiol Lung Cell Mol Physiol 2005;288:L749-L760.

110 Etienne S, Adamson P, Greenwood J, Strosberg AD, Cazaubon S, Couraud PO: ICAM1 signaling pathways associated with Rho activation in microvascular brain endothelial cells. J Immunol 1998;161:5755-5761.

- 111 Adamson P, Etienne S, Couraud PO, Calder V, Greenwood J: Lymphocyte migration through brain endothelial cell monolayers involves signaling through endothelial ICAM-1 via a Rho-dependent pathway. J Immunol 1999;162:2964-2973.

112 Wojciak-Stothard B, Williams L, Ridley AJ: Monocyte adhesion and spreading on human endothelial cells is dependent on Rhoregulated receptor clustering. J Cell Biol 1999;145:1293-1307.

113 Etienne-Manneville S, Manneville JB, Adamson P, Wilbourn B, Greenwood J, Couraud PO: ICAM-1-coupled cytoskeletal rearrangements and transendothelial lymphocyte migration involve intracellular calcium signaling in brain endothelial cell lines. J Immunol 2000;165:3375-3383.

114 Thompson PW, Randi AM, Ridley AJ: Intercellular adhesion molecule (ICAM)-1, but not ICAM-2, activates RhoA and stimulates c-fos and RhoA transcription in endothelial cells. J Immunol 2002;169:1007-1013.

115 van Buul JD, Allingham MJ, Samson T, Meller J, Boulter E, Garcia-Mata R, Burridge $\mathrm{K}$ : RhoG regulates endothelial apical cup assembly downstream from ICAM1 engagement and is involved in leukocyte trans-endothelial migration. J Cell Biol 2007;178: 1279-1293.

116 Pannekoek WJ, van Dijk JJ, Chan OY, Huveneers S, Linnemann JR, Spanjaard E, Brouwer PM, van der Meer AJ, Zwartkruis FJ, Rehmann H, de Rooij J, Bos JL: Epac1 and PDZ-GEF cooperate in Rap1 mediated endothelial junction control. Cell Signal 2011;23:2056-2064.
117 Noda K, Zhang J, Fukuhara S, Kunimoto S, Yoshimura M, Mochizuki N: Vascular endothelial-cadherin stabilizes at cell-cell junctions by anchoring to circumferential actin bundles through alpha- and beta-catenins in cyclic AMP-Epac-Rap1 signal-activated endothelial cells. Mol BiolCell 2010;21:584-596.

118 Kooistra MR, Corada M, Dejana E, Bos JL: Epac1 regulates integrity of endothelial cell junctions through VE-cadherin. FEBS Lett 2005;579:4966-4972.

119 Fukuhara S, Sakurai A, Sano H, Yamagishi A, Somekawa S, Takakura N, Saito Y, Kangawa K, Mochizuki N: Cyclic AMP potentiates vascular endothelial cadherin-mediated cell-cell contact to enhance endothelial barrier function through an Epac-Rap1 signaling pathway. Mol Cell Biol 2005;25:136-146.

120 Cullere X, Shaw SK, Andersson L, Hirahashi J, Luscinskas FW, Mayadas TN: Regulation of vascular endothelial barrier function by Epac, a cAMP-activated exchange factor for Rap GTPase. Blood 2005;105:1950-1955.

121 Birukova AA, Zagranichnaya T, Alekseeva E, Bokoch GM, Birukov KG: Epac/Rap and PKA are novel mechanisms of ANP-induced Rac-mediated pulmonary endothelial barrier protection. J Cell Physiol 2008;215:715-724.

122 Pannekoek WJ, Kooistra MR, Zwartkruis FJ, Bos JL: Cell-cell junction formation: the role of Rap1 and Rap1 guanine nucleotide exchange factors. Biochim Biophys Acta 2009; 1788:790-796.

123 Orlova VV, Economopoulou M, Lupu F, Santoso S, Chavakis T: Junctional adhesion molecule- $\mathrm{C}$ regulates vascular endothelial permeability by modulating VE-cadherinmediated cell-cell contacts. J Exp Med 2006; 203:2703-2714.

124 Martin-Padura I, Lostaglio S, Schneemann M, Williams L, Romano M, Fruscella P, Panzeri C, Stoppacciaro A, Ruco L, Villa A, Simmons D, Dejana E: Junctional adhesion molecule, a novel member of the immunoglobulin superfamily that distributes at intercellular junctions and modulates monocyte transmigration. J Cell Biol 1998;142:117-127.

125 Mandell KJ, Babbin BA, Nusrat A, Parkos CA: Junctional adhesion molecule 1 regulates epithelial cell morphology through effects on beta1 integrins and Rap1 activity. J Biol Chem 2005;280:11665-11674.

126 Wittchen ES, Worthylake RA, Kelly P, Casey PJ, Quilliam LA, Burridge K: Rap1 GTPase inhibits leukocyte transmigration by promoting endothelial barrier function. J Biol Chem 2005;280:11675-11682.

-127 van Buul JD, Voermans C, van den Berg V, Anthony EC, Mul FP, van Wetering S, van der Schoot CE, Hordijk PL: Migration of human hematopoietic progenitor cells across bone marrow endothelium is regulated by vascular endothelial cadherin. J Immunol 2002;168:588-596. 